\title{
Polícia e Saúde: entrevista com o Diretor Geral de Saúde da Polícia Militar do Estado do Rio de Janeiro
}

\author{
Police and Health: interview with the Director-General of Health \\ of the Military Police for the State of Rio de Janeiro
}

Este Diretor Geral de Saúde em atenção às questões formuladas como parte da entrevista da Revista Ciência \& Saúde Coletiva da Fundação Oswaldo Cruz presta as seguintes informações:
(1) Coloque seu nome, patente e função que exerce na Polícia.

Resposta: Coronel Médico da Polícia Militar Alberto Alves Borges, Diretor Geral de Saúde da Polícia Militar do Estado do Rio de Janeiro.

(2) Explique, resumidamente, exatamente a que corresponde essa função (tendo em vista que a maioria da população não conhece o funcionamento hierárquico da Polícia).

Resposta: As principais funções do Diretor Geral de Saúde são:

I. Coordenar as Unidades de Saúde da PMERJ que hoje compreendem 2 Hospitais, 4 Policlínicas, localizadas nos bairros de Cascadura, Olaria, São João de Meriti e na Cidade de Campos dos Goitacazes e um Centro de Fisioterapia e Reabilitação;

II. Implementar políticas de saúde para o Sistema de Saúde da Polícia Militar;

III. Gerir junto ao Comandante Geral e ao Chefe do Estado Maior da Polícia Militar os recursos do Fuspom (Fundo de Saúde da Polícia Militar);

IV. Planejar junto ao Comando da Corporação o apoio de Resgate e Remoção nas ações de campo da tropa da PMERJ;

V. Planejar, implementar a assistência médica hospitalar aos Policiais Militares e seus dependentes diretos. do Rio de Janeiro. Rua

Evaristo da Veiga 78/3

Centro. 20031-010 Rio de Janeiro RJ. 
(3) Descreva brevemente os principais problemas de saúde física e mental dos Policiais Militares do Estado do Rio de Janeiro

Resposta: O trabalho policial militar é considerado extremamente desgastante, sendo caracterizado por constante exposição ao perigo, violência e riscos iminentes, horários de trabalho noturno, horários irregulares para alimentação, exposição constante ao sol, chuva e vento, períodos longos em posição ortostática (em pé), podendo acarretar sobrecarga física e emocional ao profissional, tendo inclusive repercussões na sua vida familiar, na sua qualidade de vida, nas relações sociais que estabelece e na sua saúde.

Estudo realizado por oficiais do Quadro de Saúde da corporação (ROCHA, VARGAS, HUGUENIN, 2009) traçou o perfil das condições de saúde e trabalho dos policiais militares da PMERJ, a partir da aplicação de um questionário a 63,7\% do efetivo, no período de 2006 a 2007. Os resultados indicaram a presença de quadro de hipertensão arterial sistêmica (HAS) no efetivo estudado com prevalência superior ao encontrado na população carioca, alarmante prevalência de excesso de peso, altíssima prevalência de sedentarismo.

No que diz respeito à saúde mental dos policiais militares, os dados do Setor de Estatística da Diretoria Geral de Saúde, obtidos através do Controle Ambulatorial dos Atendimentos (CAAL) da Psicologia, no ano de 2009, apontam para a seguinte distribuição de diagnósticos em policiais militares da ativa: transtornos neuróticos e transtornos relacionados ao estresse (70\%), transtornos de humor (18\%), outros transtornos mentais e comportamentais (5\%). Ressalta-se que a frequência dos diagnósticos diz respeito ao universo de policiais militares da ativa que foram atendidos, no referido ano, pelos serviços de Psicologia existentes nas diversas Unidades.

Um parâmetro importante para a avaliação dos principais problemas de saúde física e mental dos policiais militares relaciona-se aos motivos de afastamento da atividade-fim. Dados da Seção de Perícias Médicas da PMERJ, no período compreendido entre 2009-2010, indicam que as principais causas que motivaram a concessão de licença para tratamento de saúde (LTS), tanto para oficiais quanto para praças, foram: lesões derivadas de causas externas, transtornos mentais e comportamentais, doenças do sistema osteomuscular. No que diz respeito às principais causas que motivaram a concessão de licenças, em suas várias modalidades, que abrange desde o total afastamento da atividade laborativa até a readaptação do militar, temos: doenças do sistema osteomuscular, lesões derivadas de causas externas, doenças do aparelho circulatório, sendo relevante também citar os transtornos mentais e comportamentais que figuram como a quarta causa relacionada a este tipo de afastamento.

(4) Fale brevemente sobre os Programas de Saúde existentes na Polícia (Promoção, Prevenção e Assistência inclusive hospitalar). Esses programas contemplam o pessoal da capital e do interior?

\section{Resposta:}

Programa de Imunização. Atualmente na Polícia Militar do Estado do Rio de Janeiro (PMERJ) são desenvolvidas atividades de imunização de rotina para dependentes de policiais militares e inativos e Campanhas de multivacinação (sarampo, rubéola, coqueluche, hepatite $B$, tétano, difteria e gripe) direcionadas para os policiais da ativa e servidores civis da PMERJ, iniciada pela Diretoria Geral de Saúde no ano de 2006. Desde então, já foram realizadas 10 campanhas de vacinação. O programa é baseado na Lei no 6.259 , de 30 de outubro de 1975, que dispõe sobre a organização das ações de Vigilância Epidemiológica, sobre o Programa Nacional de Imunizações e estabelece normas relativas à notificação compulsória de doenças.

Serviço de Atenção à Saúde do Policial Militar (SAS). Este projeto possui um "piloto" implantado no $31^{\circ}$ BPM (Batalhão da Polícia Militar / Barra da Tijuca) nesta capital, e tem por objetivo tratar do Policial Militar como um profissional que precisa ser acompanhado continuamente pelo Sistema de Saúde, sob a ótica da Saúde do Trabalhador, como ocorre nas grandes empresas e modernas instituições, contemplando a pluralidade de atribuições existentes na Corporação e a exposição aos riscos profissionais peculiares no seu processo de trabalho. É um projeto de sucesso que está em andamento com expectativa de ser ampliado para todos os batalhões da Polícia Militar.

Estes programas são prioridade na política de saúde da PMERJ, sendo o Programa de Imunização já devidamente implantado atinge hoje $100 \%$ do território estadual. O Serviço de Atenção à Saúde do Policial Militar (SAS) encontra-se em fase de implementação, já demonstrando numa análise inicial resultados positivos em sua eficácia quanto à prevenção de doenças e promoção da saúde. 
(5) Como percebe o interesse do meio acadêmico em estudar as questões de saúde dos policiais? Quais considera serem as contribuições desses estudos e como julga que poderiam potencializar os resultados encontrados?

Resposta: Hoje observo um crescente interesse do meio acadêmico em realizar estudos e pesquisas junto ao nosso público alvo, até em função das peculiaridades desta população, muitas decorrentes da atividade Policial Militar.

Os Oficiais de Saúde da PMERJ desenvolvem monografias voltadas à área de saúde do Policial Militar durante dois cursos distintos: Curso de Aperfeiçoamento de Oficiais e Curso Superior de Polícia. Estas monografias têm trazido valiosas informações epidemiológicas da população Policial Militar, projetos de programas de prevenção em saúde, projetos de gestão em saúde e resultados de intervenções implementadas por projetos que estão em execução, trazendo assim um feedback e permitindo avaliar os projetos implantados.

A população composta pelos Policiais Militares ativos, inativos, dependentes e pensionistas é um excelente universo amostral para estudos clínicos, pois se trata de uma população atendida por um sistema "fechado", com uma massa crítica significativa (cerca de 180.000 vidas) e com relativa facilidade de levantamento de dados.

Desta forma, as monografias realizadas pelos Oficiais de Saúde na Escola Superior da Polícia Militar e os estudos oriundos do meio acadêmico externo à corporação vêm sendo a principal fonte de informações utilizadas por esta Diretoria Geral de Saúde para nortear a implementação de novas políticas de saúde e para avaliar e ajustar àquelas medidas já implantadas.

(6) Segundo seu ponto de vista, que passos futuros deveriam ser dados para a melhoria das condições de saúde dos Policiais Militares do Estado do Rio de Janeiro.

Resposta: Esta Diretoria possui hoje três importantes projetos em andamento:

I. A construção de um novo Hospital Central da Polícia Militar que vai dobrar a capacidade instalada de leitos hospitalares, atendendo assim ao grande aumento da demanda de atendimentos em decorrência da política de expansão do número de Policiais Militares para atender às UPP (Unidades de Polícia Pacificadora) e aos grandes eventos que serão realizados na Cidade do Rio de Janeiro.

II. Informatização do Sistema de Saúde da Polícia Militar que prevê a implantação do Prontuário Único Eletrônico do Paciente que trará um grande avanço em qualidade, tanto no atendimento ao usuário como na gestão da saúde.

III. Implantação do Serviço de Atenção à Saúde do Policial Militar (SAS) que como já citamos trará ao Policial Militar da Ativa a medicina voltada à Saúde do Trabalhador, conceito ligado à prevenção das doenças ocupacionais, contemplando a pluralidade de atribuições existentes na Corporação e a exposição aos riscos profissionais peculiares no seu processo de trabalho. 
